\title{
A List Birds Observed on a Short Trip in Central and Northen Chile
}

\section{Michio FuKudA}

Tokyo Sea Life Park, 6-2-3 Rinkai-cho, Edogawa-ku, Tokyo 134

The author visited Chile from November 7th to 16th, 1996. The purpose of this trip was to conduct research on habitats of the Humboldt Penguin Spheniscus humboldti (Fig. 1). Local transportation during the research was by private automobile, with the expectation of airlines taken from Santiago to El Salvador and Copiapo to Santiago. I enjoyed many opportunities to observe Chilean birds in various areas, around the penguin colonies, in urban parks and gardens, and along the road and sea when travelling. As Chilean birds are rarely reported in Japan, a list of observed species, along with the number of individuals observed at eight locations, is provided below. The eight locations include Santiago, which is the capital of Chile; Algarrobo, where a Humboldt Penguin colony is located; Cachagua, another colony site on a large isolate off the central Chile coast; Chanaral, a miming village where I stayed in northen Chile; Pan de Azucal, a small island with a penguin colony; Isela Grande, another a small island with a penguin colony; and the suburbs and city of Copiapo. These areas are located in regions of moderate or dry climate.



Fig. 1. Humboldt Penguins in Algarrobo colony on November 10, 1996.

Key words: Bird list, Humboldt Penguin habitat, Chile. キーワード：鳥類リスト, フンボルトペンギン生息地, チリ. 
Table 1. List of Birds Observed in Eight Locations in Middle and Northern Chile : November 8 to 14, 1996.

\begin{tabular}{|c|c|c|c|c|}
\hline & \multirow{2}{*}{ Species } & & \multicolumn{2}{|c|}{ Locations } \\
\hline & & & Santiago & Algarrobo \\
\hline 1. Hornby's Storm Petrel & Oceanodroma hombyi & チリウミッバメ & & \\
\hline 2. Peruvian Diving Petrel & Pelecanoidaes gamotii & ペルーモグリウミッバメ & & \\
\hline 3. Humboldt Penguin & Spheniscus humboldti & フンボルトペンギン & & t+t \\
\hline 4. Magellanic Penguin & Spheniscus magellanicus & マグランペンギン & & + \\
\hline 5. Peruvian Booby & Sula variegata & ペルーカツオドリ & & \\
\hline 6. Brawn (Chilean) Pelican & Pelecanus thagus & かッショクペリが & & +++ \\
\hline 7. Olivaceous Cormorant & Phalacrocorax olivaceus & ナハベ们 & & t+t \\
\hline 8. Red-legged Cormorant & Phalacrocorax gaimardi & アかアシウ & & \\
\hline 9. Great Egret & Casmerodius albus & 多侀” & & + \\
\hline 10. Snowy Egret & Egretta thula & ユキサギ & & \\
\hline 11. Cattle Egret & Bubulcus ibis & アマサギ & & \\
\hline 12. Buff-necked Ibis & Theristicus caudatus & クロハラトリ & & \\
\hline 13. Black Vulture & Coragyps atratus & クロコドル & & \\
\hline 14. Turkey Vulture & Cathartes aura & ヒメコンドル & & + \\
\hline 15. Crested (Common) Caracara & Polyborus plancus & カラカラ & & \\
\hline 16. American 0ystercatcher & Haematopus ostralegus & ミヤコドリ & & \\
\hline 17. Black 0ystercatcher & Haematopus ater & ミナミクロミヤコドリ & & \\
\hline 18. Ruddy Turnstone & Arenaria interpres & キョウジョウシギ & & t+ \\
\hline 19. Baird's Sandpiper & Calidris bairdii & ヒメウズラ゙ギ & & + \\
\hline 20. Whimbrel & Numenius phaeopus & チュウシャクシギ & & + \\
\hline 21. Grey Gull & Larus modestus & ハイ㐰力モx & & \\
\hline 22. Southern Black-backed Gull & Larus dominicanus & ミカミオオやク゚咖モ & & $t+t$ \\
\hline 23. Franklin's Gull & Larus pipixcan & アメリカズグ叻モメ & & \\
\hline 24. South American Tern & Sterna hinondinacea & サシベイアジサシ & & \\
\hline 25. Elegant Tern & Sterna elegans & 坊ガアジサシ & & \\
\hline 26. Picui Ground Dove & Columbina picui & 任ンジバト & & \\
\hline 27. Borrowing $0 w 1$ & Athene cunicularia & アナ杖クリウ & & \\
\hline 28. White-throated Tapaculo & Scelorchilus albicollis & アかバ祆多テドリ & & \\
\hline 29. Rufous-naped Ground-Tyrant & Muscisaxicola nufivertex & 价タイランチョウ & & \\
\hline 30. Rufous-backed Negrito & Lessonia nufa &  & & \\
\hline 31. Blue and white Swallow & Pygochelidon cyanoleuca & アイイロッパメ & & $++t$ \\
\hline 32. House Wren & Troglodytes aedon & イエシリサザエ & & \\
\hline 33. Austral Thrush & Turdus falcklandii & フォークランドッグミ & + & \\
\hline 34. Correndera Pipit & Anthus correndera &  & & + \\
\hline 35. Bright-rumped Yellow Finch & Sicalis uropygialis & キゴシキシニジコ & & \\
\hline 36. Glassland Yellow Finch & Sicalis Iuteola & セスジキりジコ & & \\
\hline 37. Rufous-collared Sparrow & Zonotrichia capensis & アカエリシトド & t+ & \\
\hline 38. Austral Blackbird & Curaeus curaeus & ミたミム㚈リモドキ & & + \\
\hline 39. Red-back Sierra-Finch & Phyrgilus dorsalis & セアカヤマシトト゚ & & + \\
\hline 40. House Sparrow & Passer domesticus & 仜XX゙x & t+ & + \\
\hline
\end{tabular}

+ : under 9 , t+ : 10 99, t+t : over 100. 
Table 1. Continued.

\begin{tabular}{|c|c|c|c|c|c|c|}
\hline \multirow{2}{*}{ Species } & \multicolumn{6}{|c|}{ Locations } \\
\hline & Cachagua & Chanaral & $\begin{array}{l}\text { Pan de } \\
\text { Azuczl }\end{array}$ & $\begin{array}{l}\text { Isale } \\
\text { Grande }\end{array}$ & $\begin{array}{l}\text { Suburbs of } \\
\text { Copiapo }\end{array}$ & $\begin{array}{l}\text { City of } \\
\text { Copiapo }\end{array}$ \\
\hline 1. Hornby's Storm Petrel & & & & + & & \\
\hline 2. Peruvian Diving Petrel & & & & t+ & & \\
\hline 3. Humboldt Penguin & $+t+$ & & t+t & t+t & & \\
\hline 4. Magellanic Penguin & + & & & & & \\
\hline 5. Peruvian Booby & & & ++ & t+ & & \\
\hline 6. Brawn (Chilean) Pelican & t+t & & t+t & t+t & & \\
\hline 7. 0livaceous Cormorant & +++ & & t+ & H & & \\
\hline $\begin{array}{l}\text { 8. Red-legged Cormorant } \\
\text { 9. Great Egret }\end{array}$ & & & + & H & & \\
\hline $\begin{array}{l}\text { 10. Snowy Egret } \\
\text { 11. Cattle Egret }\end{array}$ & t+ & & + & & & \\
\hline 12. Buff-necked Ibis & & & & & + & \\
\hline 13. Black Vulture & + & & & & & \\
\hline 14. Turkey Vulture & + & + & + & t+ & + & \\
\hline 15. Crested (Common) Caracara & & & + & & & \\
\hline 16. American 0ystercatcher & & & + & & & \\
\hline 17. Black Oystercatcher & & & + & + & & \\
\hline 18. Ruddy Turnstone & & & & & & \\
\hline 19. Baird's Sandpiper & & & & & & \\
\hline 20. Whimbrel & & & & & & \\
\hline 21. Grey Gull & & & + & & & \\
\hline 22. Southern Black-backed Gull & t+t & t+t & t+t & t+t & & \\
\hline 23. Franklin's Gull & & & +t & & & \\
\hline 24. South American Tern & & & t+t & & & \\
\hline 25. Elegant Tern & & & & +t & & \\
\hline 26. Picui Ground Dove & & & & & t+ & \\
\hline 27. Borrowing $0 \mathrm{wl}$ & & & + & & & \\
\hline 28. White-throated Tapaculo & & & & & + & \\
\hline 29. Rufous-naped Ground-Tyrant & & & & & + & \\
\hline 30. Rufous-backed Negrito & t+ & & & & + & \\
\hline 31. Blue and white Swallow & & & & & & \\
\hline 32. House Wren & & & & & + & \\
\hline 33. Austral Thrush & & & & & & + \\
\hline 34. Correndera Pipit & & & & & & \\
\hline 35. Bright-rumped Yellow Finch & & & & & + & \\
\hline 36. Glassland Yellow Finch & & & & & + & \\
\hline 37. Rufous-collared Sparrow & & & & & & H+ \\
\hline 38. Austral Blackbird & & & & & & \\
\hline 39. Red-back Sierra-Finch & & & & & & \\
\hline 40. House Sparrow & & + & & & & + \\
\hline
\end{tabular}


A monochrome field guide (Araya and Holman 1986) written in Spanish was utilized, and a total of 40 species was identified during seven day trip (Table 1). Many other birds were observed but could not be identified. Birds seen en route were listed as in the nearest locations. Scientific and English names were based primarily Araya and Holman (1989) or Araya and Chester (1993). Japanese names were based mostly on Yamashina (1986). Ridgely and Tudor (1989a, b) and Dunning (1987) were referenced for distribution records. Araya (personal communication) noted that the Bright-rumped Yellow Finches and the Red-back Sierra Finches were rare in the areas covered by the research. I wish to thank Dr. Braulio Araya Mödinger of the honorary Professor of University of Valparaiso for his kind help in compiling this list.

\section{Cited Lituraturs}

Araya, B. and G. M. Hollman, 1986. Guia de Campo de las Aves de Chile. Editorial Universitaria, Santiago.

Araya, B. and S. Chester, 1993. The Birds of Chile. Latour, Santiago.

Dunning, J. S., 1987. South American Birds. Harrowood Books, Newtown Square and Pennsylvania.

Ridgely, R. S. and G. Tudor, 1989a. The Birds of South America. Vol. I. Oxford University Press. Oxford and Tokyo.

Ridgely, R. S. and G. Tudor, 1989b. The Birds of South America. Vol. II. Oxford University Press. Oxford and Tokyo.

Yamashina, Y., 1986. A World List of Birds with Japanese Names. Daigakushorin, Tokyo.

\section{チリの中部と北部で見た鳥類}

1996年11月 7〜16日に, フンポルトペンキンの生息地調査のためチリに行った. ペンギのコロニ 一周辺, 滞在した町や都市, また移動中などに各種の鳥類を目撃した。旅行中の前半は中部の温暖な 地域で, 後半は北部の乾燥した地域で活動した。短期間の滞在で、モノクロでスペイン語のフィール ドガイトしか持っていなかったが，40種の鳥類を記録できた。

福田道雄 : 東京都葛西臨海水族園 $\overline{1} 134$ 東京都江戸川区臨海町6-2-3 